\title{
Effect of fermentation on physico-chemical, textural properties and yoghurt bacteria in mango soy fortified yoghurt
}

\author{
Ashu Walia ${ }^{1}$, H. N. Mishra ${ }^{2}$ and Pradyuman Kumar ${ }^{1 *}$ \\ ${ }^{1}$ Department of Food Engineering and Technology, Sant Longowal Institute of Engineering and Technology, \\ Longowal - 148106 India. \\ ${ }^{2}$ Department of Agricultural and Food Engineering, Post Harvest Technology Centre, Indian Institute of Technology, \\ Kharagpur 721302 India.
}

Accepted 25 August, 2009

\begin{abstract}
Mango soy fortified yoghurt (MSFY) samples were prepared by using blends of $78.3 \%$ milk containing $3 \%$ fat, $14.5 \%$ soymilk containing $8.2 \%$ total solids and $7.2 \%$ mango pulp containing $18 \%$ total solids. The physico-chemical, textural properties and yoghurt bacteria counts of MSFY were analyzed at an interval of $30 \mathrm{~min}$ during fermentation upto $270 \mathrm{~min}$. The fermentation time had a positive effect on acidity but a negative effect on $\mathrm{pH}$, total solids and sugars in MSFY. Quadratic model were well fitted into different physico-chemical properties of MSFY during fermentation. Textural profile data of MSFY during fermentation were: hardness $(46.44-154.6 \mathrm{~g})$, cohesiveness $(0.4133-0.8137)$, adhesiveness (2.57 to -59.77 g.s), springiness $(1.037-1.416)$ and gumminess $(26.22$ - $93.80 \mathrm{~g})$. The Streptococcus thermophilus counts increased from $1.3 \times 10^{8}$ to $1.75 \times 10^{9} \mathrm{cfu} / \mathrm{ml}$ and Lactobacillus bulgaricus from 0.9 $\times 10^{8}$ to $1.17 \times 10^{9} \mathrm{cfu} / \mathrm{ml}$. Specific growth rate of $S$. thermophilus is higher than that of $L$. bulgaricus during MSFY fermentation.
\end{abstract}

Key words: Yoghurt, mango, soymilk, fermentation, texture, physico-chemical properties.

\section{INTRODUCTION}

Milk, for thousands of years, has been transformed through microbial fermentation into various food products with high nutritional value (Tamime and Robinson, 1999). Yoghurt is a coagulated milk product obtained by the lactic acid fermentation through the action of Streptococcus thermophilus and Lactobacillus delbrueckii spp. bulgaricus. The product is accepted by consumers due to its flavor and aroma, mainly attributed to acetaldehyde and texture. Viability and activity of yoghurt bacteria are important commercial considerations so that they survive throughout shelf life, transit through acidic conditions in the stomach as well as enzymes and bile salts in the small intestine.
Fortification of yoghurt with soy solids and mango pulp not only increases its nutrient content including minerals and vitamins but also adds to its health promoting value. Soymilk based yoghurt would offer several distinct nutritional advantages over milk yoghurt to the consumer, that is reduced level of cholesterol, saturated fat and lactose (Lee et al., 1990). Soybean is a good source of niacin, riboflavin, iron, potassium, calcium, magnesium and phosphorus, with several fat and water soluble vitamin B-complex (Zucker and Zucker, 1943). Addition of mango pulp adds a variety for consumer to select as they both add to the nutritional value of the yoghurt. Mango pulp contains a high proportion of sugar, mostly 
monosaccharide that is easily adsorbed by the digestive system.

Bonezar et al. (2002) studied the effects of certain factors on the properties of ewe's milk and observed that the overall properties of yoghurt, such as acidity level, the production of aroma compounds (diacetyl, aceteldehyde) as well as the nutritional value are important traits of the product. These aspects are influenced by the chemical composition of the milk base, processed conditions, the added flavors and the activity of starter culture during the incubation period. There have been many investigations involving optimization of yoghurt texture. These studies have demonstrated that the total solids and fat levels in the milk, heat treatment of the milk prior to inoculation, homogenization, presence of stabilizers (Kumar and Mishra, 2004) and incubation conditions will affect the body of the final product (Schellhaass and Morris, 1985).

Buono et al. (1990) studied the carbohydrate utilization and growth kinetics in the production of yoghurt from soymilk. Utilization of soymilk as an ingredient for human food necessitates a reduction in the concentration of the carbohydrates that can cause flatulence and a reduction in the objectionable beany flavor typically associated with soy products. The fermentation process undergoes several distinct phases based on the changes in $\mathrm{pH}$ and acidity and sugar content. The first stage has a rapid decrease of $\mathrm{pH}$ and an increase of acidity. These changes are accompanied by a decrease of reducing sugars after the initial lag phase. The next stage shows a gradual drop in $\mathrm{pH}$, a further increase in acidity and a rapid disappearance of reducing sugars. The final stage of fermentation proceeds with slight changes in $\mathrm{pH}$, acidity and reducing sugars.

In the present paper, the effect of fermentation time on physico-chemical, textural and growth kinetics of yoghurt bacteria in Mango soy fortified yoghurt (MSFY) is discussed.

\section{MATERIALS AND METHODS}

Pure freeze dried cultures of $S$. thermophilus NCDC 074 and $L$. delbrueckii spp. bulgaricus NCDC 009 were procured from National Dairy Research Institute, Karnal, India. These cultures were maintained in $12 \%$ skim milk (SM) media and autoclaved at $15 \mathrm{psi}$ for $20 \mathrm{~min}$. Toned milk used for yoghurt preparation was procured from local market and has been standardized to a fat content of $3 \%$. Soymilk was prepared in the laboratory from whole soybeans using the procedure described by Bourne et al. (1976). A canned mango pulp (Kaytis brand) containing $18 \%$ total solid was purchased from local market. These were used to prepare experimental samples.

\section{MSFY preparation}

The blend of $78.3 \%$ milk ( $3 \%$ fat), $14.5 \%$ soymilk ( $8.2 \%$ total solids) were heated to $95^{\circ} \mathrm{C}$ for $5 \mathrm{~min}$, cooled to $45^{\circ} \mathrm{C}$ and $7.2 \%$ mango pulp (18\% total solids) was added with high speed stirring. The blends were inoculated with $2 \%(\mathrm{v} / \mathrm{v}, S$. thermophilus and $L$. bulgaricus in 1:1 ratio) of $24 \mathrm{~h}$ old culture. The blend was incubated at $42 \pm 2^{\circ} \mathrm{C}$ in a plastic cup $(100 \mathrm{ml})$. Mango soy fortified yoghurt (MSFY) was prepared by as per method (Kumar and Mishra, 2003a). Samples were kept for $2 \mathrm{~h}$ at $8^{\circ} \mathrm{C}$ before analysis.

\section{Addition of inoculums}

Two cultures $S$. thermophilus and $L$. bulgaricus were used for studying the effect of fermentation time on physico-chemical properties and growth kinetics of Mango Soy Fortified Yoghurt (MSFY). The physicochemical properties of MSFY such as $\mathrm{pH}$, acidity, total solids, sugars were analyzed at an interval of $30 \mathrm{~min}$ during fermentation up to $270 \mathrm{~min}$. Microbiological and textural properties were also studied for each $30 \mathrm{~min}$ after the culture had been allowed to grow for $270 \mathrm{~min}$.

The experiments were carried out in triplicates. All physicochemical and textural properties were fitted into linear and quadratic equations to see the effect of fermentation time. The effect of fermentation time on microbial growth was described by the exponential phase. The exponential phase may be described by the equation:

$d x / d t=\mu x$

Where:

$$
\begin{aligned}
& x=\text { microbial counts }(\mathrm{cfu} / \mathrm{ml}) \\
& t=\text { time }(\mathrm{min}) \\
& \mu=\text { specific growth rate }\left(\mathrm{min}^{-1}\right) \\
& \text { Integrating Equation }(1) \text { gives: }
\end{aligned}
$$

$x_{t}=x_{0} e^{\mu t}$

Where:

$\mathrm{x}_{0}=$ original microbial counts $(\mathrm{cfu} / \mathrm{ml})$

$x_{t}=$ microbial counts after the time interval, $t(\min )$

$\mathrm{t}=$ Time $(\min )$

$\mathrm{e}=$ base of the natural logarithm.

Taking natural logarithms, Equation (2) becomes:

$\ln x_{t}=\ln x_{0}+\mu t$

Thus, a plot of natural logarithm of microbial counts of ST and LB against time should yield a straight line, the slope of which would be the value of specific growth rate. During the exponential phase, nutrients are in excess and the organism is growing at its maximum specific growth rate, $\mu_{\max }$, for the prevailing conditions (Stanbury et al., 1995).

\section{Analysis of physicochemical characteristics}

Physicochemical properties of MSFY such as $\mathrm{pH}$, titrable acidity (IDF, 1991a) and total solids (IDF, 1991b) were determined. Reducing and non reducing sugars were estimated by Lane and Eynon Method (Ranganna, 1996).

\section{Texture profile analysis}

In the recent past, instrumental texture analysis (TPA) has been applied as a useful method to evaluate mechanical properties in a 


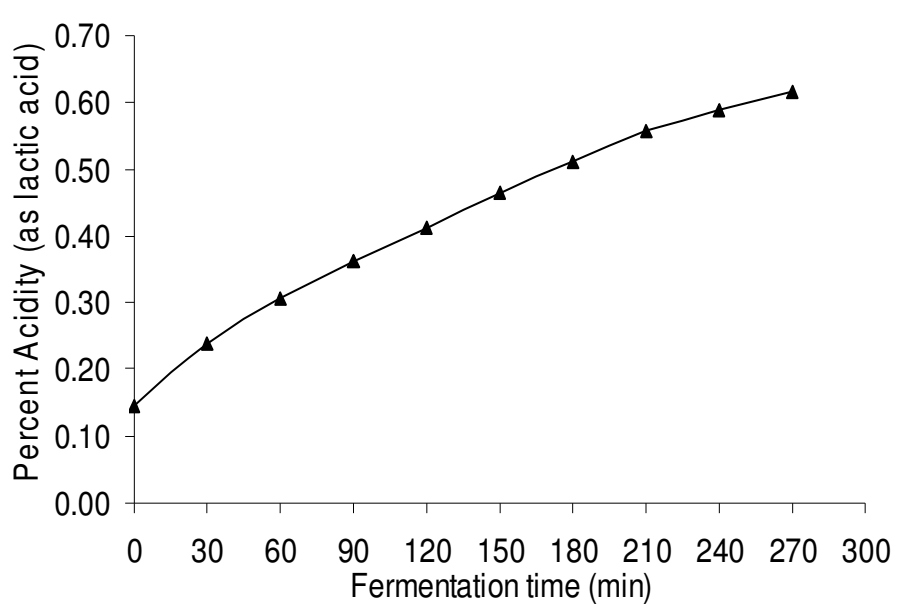

Figure 1a. Effect of fermentation time on per cent acidity (as lactic acid).

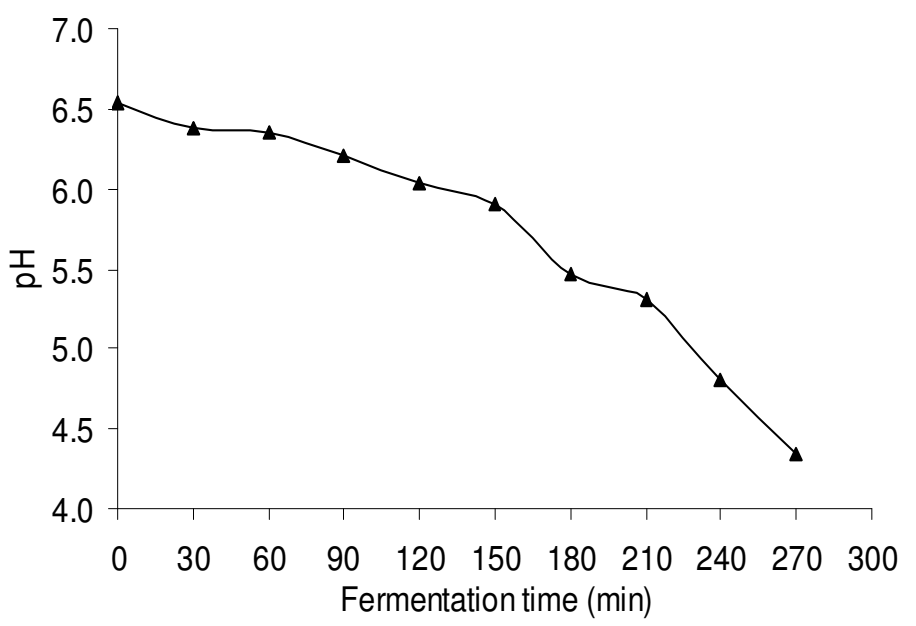

Figure 1b. Effect of fermentation time on $\mathrm{pH}$.

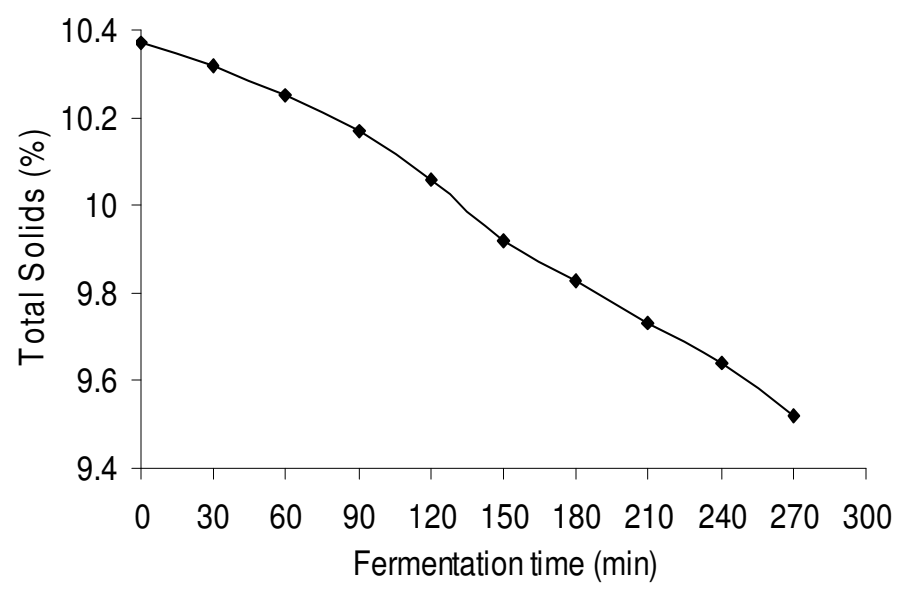

Figure 1c. Effect of fermentation time on total solids (\%).

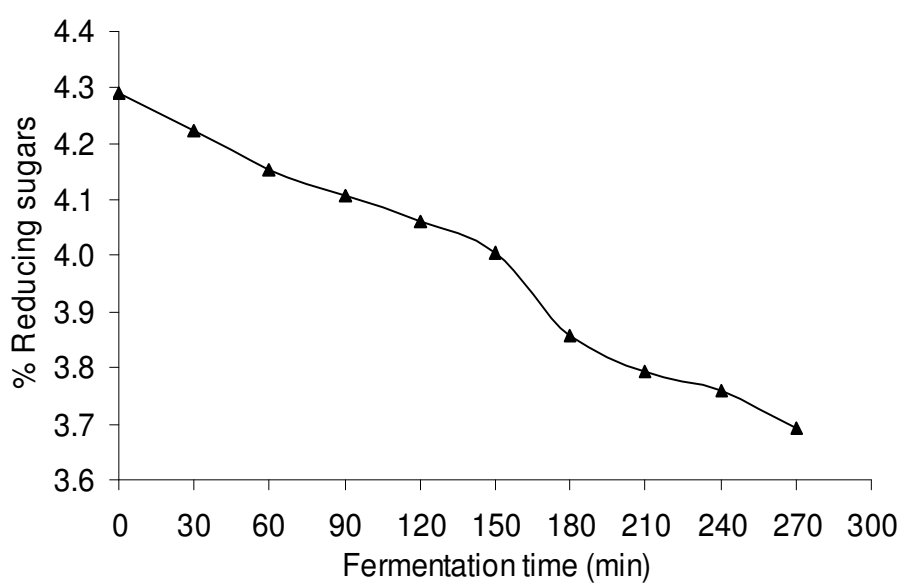

Figure 1d. Effect of fermentation time on reducing sugars (\%).

wide range of foods (Pons and Fiszman, 1996). TPA compresses a piece product twice imitating the conditions in the mouth (Szczesniak et al., 1963). Five basic textural parameters may be obtained in only one test (hardness, cohesiveness, springiness, adhesiveness and gumminess), extracted from the resulting forcetime curves. Texture profile analysis was carried out by the method described by Kumar and Mishra (2003b). The data obtained from typical texture profile curve was used for the calculation of the textural parameters (Bourne, 1978; Bourne, 1982) as follows:

Hardness, $\mathrm{g}=$ maximum force of the first compression

Cohesiveness $=\frac{\text { Area under } 2^{\text {nd }} \text { compression (Area 2) }}{\text { Area under } 1^{\text {st }} \text { compression (Area 1) }}$
Adhesiveness, g.s $=$ negative area in the graph (Area 3).

Springiness $=$ Length $2 /$ Length 1

Gumminess, $\mathrm{g}=$ Hardness $\times$ Cohesiveness

\section{Enumeration of S. thermophilus and L. bulgaricus}

International Dairy Federation methods (1988) were used for the enumeration of $S$. thermophilus and $L$. bulgaricus. The $S$. thermophilus agar (M948), L. delbrueckii subsp. bulgaricus agar (M927) produced from Hi Media Laboratories Limited, Mumbai, were used. The samples were diluted in peptone (1\%) in water. The agar plates of $S$. thermophilus were incubated aerobically at $37^{\circ} \mathrm{C}$ for $48 \mathrm{~h}$ while the plates of $L$. bulgaricus were incubated at $37^{\circ} \mathrm{C}$ for $72 \mathrm{~h}$ under anaerobic conditions. After incubation, typical colonies of $S$. thermophilus and $L$. bulgaricus were counted. Plates with $30-$ 300 colonies were used in counting and the counts were averaged for three replicates and expressed as c.f.u/ml.

The significance of fermentation time was determined through Single factor analysis (ANOVA) of the data obtained in three experimental runs.

\section{RESULTS AND DISCUSSION}

The results of different physico-chemical parameters that is, acidity, $\mathrm{pH}$, total solids, reducing sugars and total sugars are shown in Figures 1a to 1e. The fermentation time 
Table 1. Linear and quadratic models of different physico-chemical properties of MSFY.

\begin{tabular}{lccccccc}
\hline \multirow{2}{*}{ Parameters } & \multicolumn{3}{c}{ Linear model $(\mathbf{y}=\mathbf{m} \mathbf{x}+\mathbf{c})$} & \multicolumn{3}{c}{ Quadratic model $\left(\mathbf{y}=\mathbf{a x}^{\mathbf{2}}+\mathbf{b x}+\mathbf{c}\right)$} \\
\cline { 2 - 7 } & $\mathbf{m}$ & $\mathbf{c}$ & $\mathbf{R}^{2}$ & $\mathbf{a}$ & $\mathbf{b}$ & $\mathbf{c}$ & $\mathbf{R}^{\mathbf{2}}$ \\
\hline Acidity & 0.0017 & 0.191 & 0.979 & $-3 \times 10^{-6}$ & 0.0026 & 0.1569 & 0.998 \\
pH & -0.0077 & 6.7781 & 0.922 & $-3 \times 10^{-5}$ & $-4 \times 10^{-5}$ & 6.4699 & 0.994 \\
Total solids & -0.0033 & 10.422 & 0.992 & $-3 \times 10^{-6}$ & -0.0025 & 10.393 & 0.996 \\
Reducing sugars & -0.0023 & 4.3002 & 0.985 & $-1 \times 10^{-6}$ & -0.002 & 4.2895 & 0.986 \\
Total sugars & -0.0022 & 4.939 & 0.994 & $-1 \times 10^{-6}$ & -0.0019 & 4.9272 & 0.995 \\
\hline
\end{tabular}

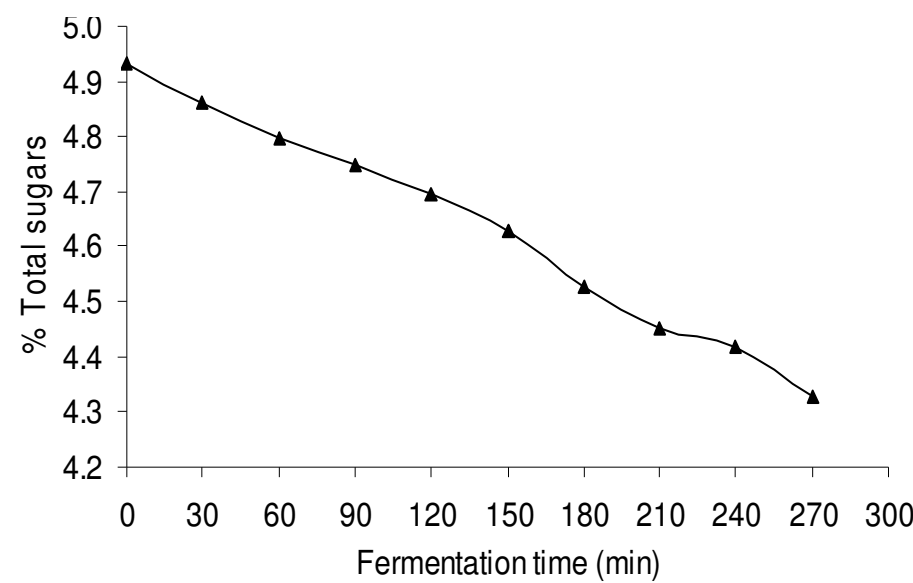

Figure 1e. Effect of fermentation time on total sugars (\%) of MSFY.

had a positive effect on acidity but a negative effect on $\mathrm{pH}$, total solids, reducing and total sugars in MSFY (Table 1). The acidity of MSFY as \% lactic acid increased from 0.15 at 0 min to 0.62 at 270 min of fermentation and total solids decreased from 10.37 to 9.52 . The $\mathrm{pH}$ decreased from 6.53 to 4.34 and total sugars from 4.93 to 4.33 at these fermentation times.

Different culture combination of $S$. thermophilus (HST, 197) and L. bulgaricus (RTS, Yb) were studied for total acid production in cow milk and buffalo milk from $2-10 \mathrm{~h}$ of incubation. It was observed that with the increase in incubation time, there was an increase in acid production in the culture combinations of different strains in both types of milk. Earlier reports by Macquot and Hurrel (1970) and Tramer (1973) have indicated that with the increase in fermentation time, there was an increase in acid production in the culture combinations of different strains in both cow and buffalo milk from 10 to $12 \mathrm{~h}$ of incubation. In yoghurt, lactose utilization proceeds as long as the external $\mathrm{pH}$ allows metabolic activity of the lactic acid bacteria. When lactic acid is produced in yoghurt and $\mathrm{pH}$ has reached $4.0, L$. bulgaricus cease their metabolic activity and lactose is no further utilized. By rerouting metabolism of the lactic acid bacteria towards production of more $\mathrm{pH}$-neutral components, further conversion of lactose is possible (de Vos, 1996).
Goodenough and Kleyn (1976) investigated qualitative and quantitative changes in sugars of yoghurt during its manufacture and reported average lactose concentration of $8.5 \%$ in yoghurt mix which dropped to $5.75 \%$ with a concomitant increase of $1.20 \%$ galactose. Glucose was detected only in trace quantities. Commercial yoghurts had an average of $4.06 \%$ lactose, $1.85 \%$ galactose, $0.05 \%$ glucose.

The dependency of response variables on coefficients associated with linear and quadratic equations and their significance with coefficient of determination $\left(R^{2}\right)$ of physicochemical properties is shown in Table 1. High coefficient of determination $\left(R^{2}\right)$ explained the goodness of fit in the experimental data. The quadratic model was found to be suitable than corresponding linear model for each physico-chemical property. The fermentation time had significant $(P<0.01)$ effects after analyzing the data for different experimental runs through Single factor analysis (ANOVA) (Table 2) on all physico-chemical characteristics of yoghurt sample during fermentation.

\section{Textural characteristics}

Yoghurt rheology is described not only in terms of viscosity, viscosity loss and its recovery, but is also described in terms of how hard, brittle, elastic and cohesive it is. Textural characteristics and rheological properties of coagulated dairy products are affected by their structural characteristics. The structural arrangement of the network determines the textural characteristics of these coagulated products and is affected by factors such as composition and manufacturing processes (Rawson and Marshall, 1997). Force measuring instruments like the TA-XT2 texture analyzer allow food materials to be evaluated in such terms and have been used to assess yoghurt texture (Toba et al., 1990; Kaur et al., 2009).

TPA curves of MSFY were obtained during fermentation at 120,150,180, 210, 240 and 270 min fermentation time. TPA curves at $0,30,60,90$ min were not possible as the force required by the probe to mea-sure TPA curves was not attained at these fermentation times. The results of different TPA curves are summarized in Table 3.

Hardness (force necessary to attain a given deformation) is a commonly evaluated parameter when 
Table 2. Single factor analysis (ANOVA) for physico-chemical properties and S. thermophilus (ST) and L. bulgaricus (LB) counts of MSFY.

\begin{tabular}{|c|c|c|c|c|c|c|c|}
\hline $\begin{array}{l}\text { Physico-chemical and } \\
\text { microbiological properties }\end{array}$ & Source of variation & $\begin{array}{l}\text { Sum of squares } \\
\text { (SS) }\end{array}$ & $\begin{array}{c}\text { Degree of } \\
\text { Freedom (df) }\end{array}$ & $\begin{array}{c}\text { Mean sum } \\
\text { of square (MSS) }\end{array}$ & $\begin{array}{l}\text { Calculated } \\
\mathrm{F} \text { - value }\end{array}$ & P-value & F-critical \\
\hline \multirow{3}{*}{ Acidity } & Fermentation time & 90557.98 & 1 & 90557.98 & 21.95 & $1.84 \times 10^{-4}$ & 4.41 \\
\hline & Error & 74250.2 & 18 & 4125.01 & & & \\
\hline & Total & 165808.2 & 19 & & & & \\
\hline \multirow{3}{*}{$\mathrm{pH}$} & Fermentation time & 83550.65 & 1 & 83550.65 & 20.25 & $2.77 \times 10^{-4}$ & 4.41 \\
\hline & Error & 74254.83 & 18 & 4125.27 & & & \\
\hline & Total & 157805.5 & 19 & & & & \\
\hline \multirow{3}{*}{ Total solids } & Fermentation time & 78148.75 & 1 & 78148.75 & 18.94 & $4.32 \times 10^{-4}$ & 4.41 \\
\hline & Error & 74250.8 & 18 & 4125.04 & & & \\
\hline & Total & 152399.6 & 19 & & & & \\
\hline \multirow{3}{*}{ Reducing sugars } & Fermentation time & 85812.42 & 1 & 85812.42 & 20.80 & $2.42 \times 10^{-4}$ & 4.41 \\
\hline & Error & 74250.39 & 18 & 4125.02 & & & \\
\hline & Total & 160062.8 & 19 & & & & \\
\hline \multirow{3}{*}{ Total sugars } & Fermentation time & 84970.82 & 1 & 84970.82 & 20.60 & $2.54 \times 10^{-4}$ & 4.41 \\
\hline & Error & 74250.37 & 18 & 4125.02 & & & \\
\hline & Total & 159221.2 & 19 & & & & \\
\hline \multirow{3}{*}{ ST } & Fermentation time & 25063.2 & 1 & 25063.2 & 5.24 & $3.44 \times 10^{-2}$ & 4.41 \\
\hline & Error & 86108.27 & 18 & 4783.793 & & & \\
\hline & Total & 111171.5 & 19 & & & & \\
\hline \multirow{3}{*}{ LB } & Fermentation time & 32213.69 & 1 & 32213.69 & 6.62 & $1.92 \times 10^{-2}$ & 4.41 \\
\hline & Error & 87613.51 & 18 & 4867.417 & & & \\
\hline & Total & 119827.2 & 19 & & & & \\
\hline
\end{tabular}

Table 3. Textural profile data of TPA curves at different fermentation time of MSFY.

\begin{tabular}{cccccc}
\hline Fermentation time $(\mathbf{m i n})$ & Hardness $\mathbf{( g )}$ & Cohesiveness & Adhesiveness (g.s) & Springiness & Gumminess (g) \\
\hline 120 & 46.44 & 0.5646 & -2.57 & 1.126 & 26.22 \\
150 & 63.6 & 0.4133 & -5.48 & 1.078 & 26.28 \\
180 & 66.9 & 0.4906 & -5.49 & 1.416 & 32.82 \\
210 & 76.6 & 0.3674 & -22.71 & 1.067 & 28.14 \\
240 & 93.1 & 0.8137 & -43.30 & 1.066 & 75.76 \\
270 & 154.6 & 0.6067 & -59.77 & 1.037 & 93.80 \\
\hline
\end{tabular}

determining yoghurt texture. Hardness of yoghurt increases with the increase in fermentation time. The hardness of the yoghurt increases with the duration of heating and has been attributed to sulphydral groups (Vijayananda et al., 1989). During the fermentation period of milk, gel is produced to make yoghurt, thus increasing the hardness. In semi solid like products, cohesiveness represents how well the product withstands a second deformation relative to how it behaved under the first deformation. An important characteristic of TPA curve is the negative area between the first and second compression cycle which corresponds to adhesiveness of product. Adhesiveness is the force necessary to remove the material that adheres to the mouth during eating. Springiness is the rate at which the sample returns to its original shape when the deforming force is removed. The textural data of MSFY were hardness (46.44 to $154.6 \mathrm{~g}$ ), cohesiveness (0.4133 to 0.8137$)$, adhesiveness (-2.57 to -59.77 g.s), springiness (1.037 to 1.416) and gumminess $(26.22$ to $93.80 \mathrm{~g})$ during fermentation of MSFY. Hardness, gumminess, springiness, adhesiveness and cohesiveness were significantly $(P<0.01)$ affected by 
Table 4. Analysis of variance (ANOVA) for textural properties of MSFY.

\begin{tabular}{|c|c|c|c|c|c|c|c|}
\hline $\begin{array}{l}\text { Properties of } \\
\text { MSFY }\end{array}$ & $\begin{array}{c}\text { Source of } \\
\text { variation }\end{array}$ & $\begin{array}{c}\text { Sum of } \\
\text { Squares (SS) }\end{array}$ & $\begin{array}{c}\text { Degree of } \\
\text { freedom (df) }\end{array}$ & $\begin{array}{c}\text { Mean sum } \\
\text { of square (MSS) }\end{array}$ & $\begin{array}{c}\text { Calculated } \\
\text { F - value }\end{array}$ & P-value & F-critical \\
\hline \multirow{3}{*}{ Hardness } & Fermentation time & 46720.13 & 1 & 46720.13 & 25.03 & $5.35 \times 10^{-4}$ & 4.96 \\
\hline & Error & 18663.72 & 10 & 1866.37 & & & \\
\hline & Total & 65383.85 & 11 & & & & \\
\hline \multirow{3}{*}{ Cohesiveness } & Fermentation time & 113440.9 & 1 & 113440.90 & 72.03 & $6.99 \times 10^{-6}$ & 4.96 \\
\hline & Error & 15750.13 & 10 & 1575.01 & & & \\
\hline & Total & 129191 & 11 & & & & \\
\hline \multirow{3}{*}{ Adhesiveness } & Fermentation time & 142859.9 & 1 & 142859.9 & 77.03 & $5.18 \times 10^{-6}$ & 4.96 \\
\hline & Error & 18544.85 & 10 & 1854.485 & & & \\
\hline & Total & 161404.8 & 11 & & & & \\
\hline \multirow{3}{*}{ Springiness } & Fermentation time & 112754.8 & 1 & 112754.8 & 71.59 & $7.18 \times 10^{-5}$ & 4.96 \\
\hline & Error & 15750.1 & 10 & 1575.01 & & & \\
\hline & Total & 128504.9 & 11 & & & & \\
\hline \multirow{3}{*}{ Gumminess } & Fermentation time & 72732.75 & 1 & 72732.75 & 40.53 & $8.18 \times 10^{-5}$ & 4.96 \\
\hline & Error & 17945.5 & 10 & 1794.55 & & & \\
\hline & Total & 90678.25 & 11 & & & & \\
\hline
\end{tabular}

fermentation time (Table 4).

\section{Yoghurt bacteria counts}

During incubation, as the starter culture grows, a positive interaction is generally observed between $S$. thermophilus and L. bulgaricus mixed cultures. The $S$. thermophilus and the $L$. bulgaricus are inoculated simultaneously at 1:1 composition, for instance and remain present throughout the production of yoghurt, as well as in the final product. When both bacteria grow in association, the times for milk coagulation are faster than if either of them is grown separately. The $S$. thermophilus grow and, while they grow, they produce formic acid that, in turn, stimulates the growth of the L. bulgaricus. The activity of the latter on casein induces the presence of free amino acids, which, in turn, stimulate the growth of the former (Ginovert et al., 2002).

Production of MSFY involves batch culture fermentation. There were marked changes in starter counts with the fermentation time. Data were plotted as the logarithm of the microbial counts of ST and LB as shown in Figure $2 \mathrm{a}$ and $2 \mathrm{~b}$. Batch growth curves are prepared based on measurement of viable cell counts (VCC) for L. bulgaricus and S. thermophilus. As shown in Figure 2, both organisms displayed relatively straight line plots. The $S$. thermophilus and $L$. bulgaricus counts increased from 0 to $270 \mathrm{~min}$ of fermentation. The $S$. thermophilus and $L$. bulgaricus counts varied from $1.3 \times$ $10^{8}$ to $1.75 \times 10^{9} \mathrm{cfu} / \mathrm{ml}$ and $0.9 \times 10^{8}$ to $1.17 \times 10^{9} \mathrm{cfu} /$ $\mathrm{ml}$, respectively.

The fermentation time had a significant effect $(P<0.05)$ on starter counts (Table 2). $F_{\text {cal }}$ value (5.24) is greater than $F_{\text {tab }}$ value (4.41) which signifies that fermentation time is significantly affecting the number of Streptococci cells at $P<0.05$. The Single factor analysis for $L$. bulgaricus counts (Table 2) also showed the significant effect of fermentation time on lactobacilli cells at $P<0.05$.

A plot of natural logarithm of microbial counts of ST and LB against time yield a straight line (Figure 2), the slope of which was the specific growth rate $\left(\mu_{\max }\right)$ for each microorganism.

\section{Variations in S. thermophilus cell numbers}

The equation for the increase in the number of streptococci cells in MSFY, 270 min after inoculation:

$\ln (\mathrm{ST})=0.0092 \times \mathrm{t}+19.145\left(\mathrm{R}^{2}=0.9012\right)$

Slope $=\mu_{\max }=0.0092$ where $\mu_{\max }$ is the maximum specific growth rate of streptococci.

\section{Variations in L. bulgaricus cell numbers}

The equation for the increase in the number of lactobacilli 


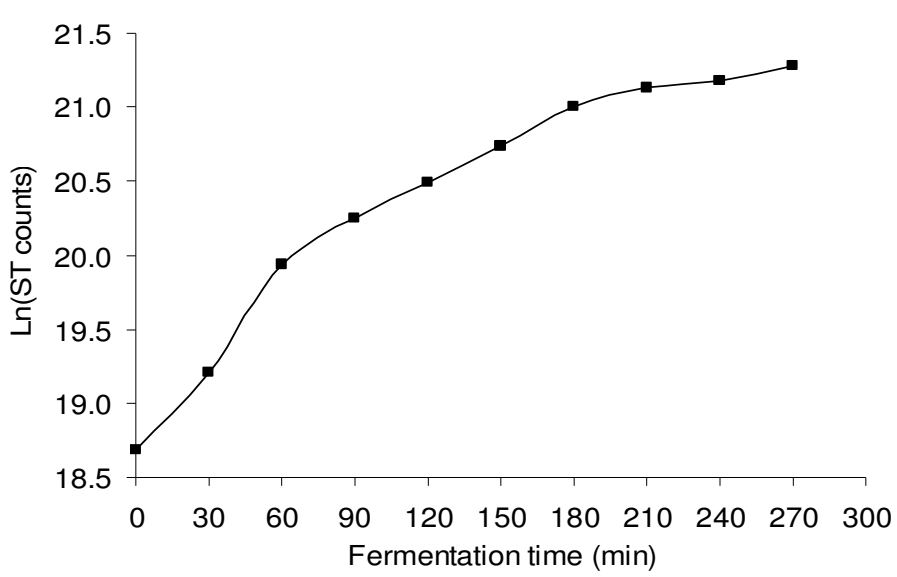

Figure 2a. Growth curves of yoghurt bacteria Streptococcus thermophilus during fermentation of MSFY.

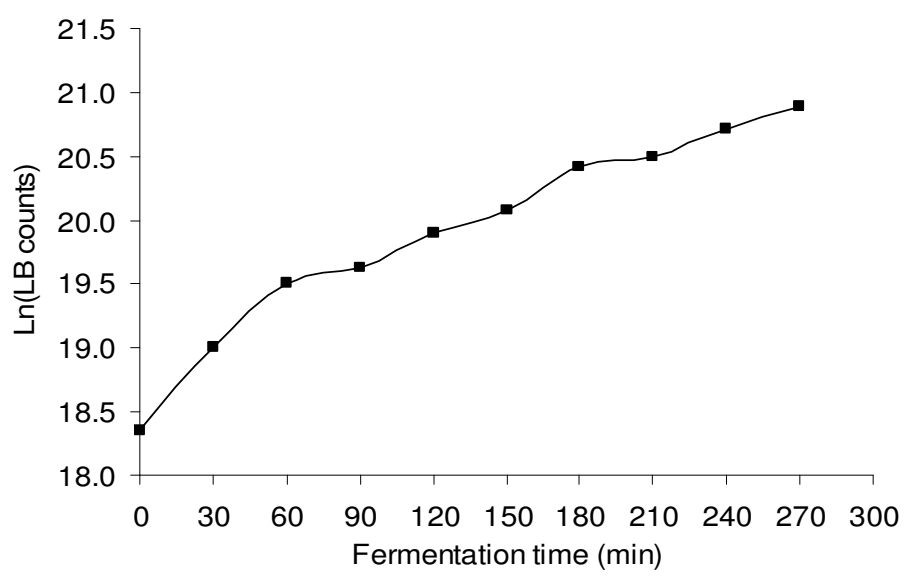

Figure 2b. Growth curves of yoghurt bacteria Lactobacillus bulgaricus during fermentation of MSFY.

cells in MSFY, 270 min after inoculation:

$\ln (\mathrm{LB})=0.0085 \times \mathrm{t}+18.745\left(\mathrm{R}^{2}=0.9475\right)$

Slope $=\mu_{\max }=0.0085$ where $\mu_{\max }$ is the maximum specific growth rate of lactobacilli.

Therefore, $\mu_{\max }$ for streptococci was larger than that for lactobacilli which indicated that $S$. thermophilus grows faster than $L$. bulgaricus. This result was in agreement with the earlier findings of Ginovert et al. (2002). They studied the simulation modeling of bacterial growth and noticed a faster increase for both $S$. thermophilus and $L$. bulgaricus in the mixed culture, a consequence of their symbiotic relation.

\section{Conclusion}

All the physico-chemical, textural properties and yoghurt bacteria counts were analyzed at an interval of $30 \mathrm{~min}$ after the two cultures that is ST and LB had been allowed to grow for $270 \mathrm{~min}$. The acidity (as \% lactic acid) increased whereas $\mathrm{pH}$, total solids and sugars decreased with the increase in fermentation time. The value of acidity of MSFY as \% lactic acid ranged from 0.15 at 0 $\min$ to 0.62 at $270 \mathrm{~min}$ of fermentation. The decrease in $\mathrm{pH}$ was from 6.53 to 4.34 and reduction in total sugars was 4.93 to 4.33 while reducing sugars decreased from 4.29 to 3.69 at these fermentation times. The TA-XT2 Texture Analyzer was used to measure the textural characteristics of MSFY. The TPA curves were obtained at $120-270 \mathrm{~min}$ of fermentation. TPA curves at $0-90 \mathrm{~min}$ were not possible as the force required by the probe to measure TPA curves was not attained at these fermentation times. The $S$. thermophilus and $L$. bulgaricus counts increased from 0 to $270 \mathrm{~min}$ of fermentation. The S. thermophilus counts increased from $1.3 \times 10^{8}$ to $1.75 \times$ $10^{9} \mathrm{cfu} / \mathrm{ml}$ and $L$. bulgaricus from $0.9 \times 10^{8}$ to $1.17 \times 10^{9}$ $\mathrm{cfu} / \mathrm{ml}$.

\section{REFERENCES}

Bonezar G, Wszolek M, Siuta, A (2002). The effects of certain factors on the properties of yoghurt made from ewe's milk. Food Chem. 79: 85-91.

Bourne MC (1978). Texture profile analysis. Food Technol. 32(7): 6272.

Bourne MC (1982). Food Texture and Viscosity: Concept and Measurement. Academic Press, New York.

Bourne MC, Escuela EE, Benzon J (1976). Effect of sodium alkali and salt on $\mathrm{pH}$ and flavor of soymilk. J. Food Sci. 41: 62- 66.

Buono M, Larry E, Fung D, Jeon IJ (1990). Carbohydrate Utilization and Growth Kinetics in the Production of Yoghurt from Soymilk Part I: Experimental Methods. J. Food Proc. Preserv. 13: 135-153.

De Vos WM (1996). Metabolic engineering of sugar catabolism in lactic acid bacteria. Anotonie van Leeuwenhoek 70: 223-242.

Ginovert M, Lopez D, Valls J, Silbert M (2002). Simulation modeling of bacterial growth in yoghurt. Int. J. Food Microbiol. 73: 415- 425.

Goodenough ER, Kleyn DA (1976). Qualitatative and quantitative changes in carbohydrates during the manufacture of yoghurt. J. Dairy Sci. 59: 45-47.

International Dairy Federation (1988). Yoghurt: Enumeration of characteristics organisms-colony count technique at $37^{\circ} \mathrm{C}$. IDF Standard No. 117 A Brussels.

International Dairy Federation (1991a). Yoghurt- determination of titrable acidity- potentiometric method. IDF Standard No. 150 Brussels.

International Dairy Federation (1991b). Yoghurt- determination of total solids IDF Standard No. 151 Brussels.

Kaur H, Mishra HN, Kumar P (2009). Textural properties of mango soy fortified probiotic yoghurt: optimization of inoculum level of yoghurt and probiotic culture. Int. J. Food Sci. Technol. 44(2): 415-424.

Kumar P, Mishra HN (2003a). Optimization of Mango soy fortified yoghurt formulation using response surface methodology. Int. J. Food Prop. 6(3): 499-517.

Kumar P, Mishra HN (2003b). Effect of mango pulp and soymilk fortification on textural profile of set yoghurt made from buffalo milk. J. Texture Stud. 34(3): 249-269.

Kumar P, Mishra HN (2004). Mango soy fortified set yoghurt: effect of stabilizer addition on physico-chemical, sensory and textural properties. Food Chem. 87: 501-507.

Lee SY, Morr CV, Seo A (1990). Comparison of milk based and soymilk based yoghurt. J. Food Sci. 55(2): 532-536. 
Macquot G, Hurrel C (1970). The Selection and use of some micro-orgs for the manufacture of fermented and acidified milk products. J. Soc. Dairy Technol. 23: 130.

Pons M, Fiszman SM (1996). Instrumental texture profile analysis with particular reference to gelled systems. J. Texture Stud. 27: 597-624.

Ranganna S (1996). Handbook of analysis and quality control for fruit and vegetable products. Tata McGraw-Hill Publishing Co. Ltd.

Rawson HL, Marshall VM (1997). Effect of ropy strains of Lactobacillus delbrueckii ssp. bulgaricus and Streptococcus thermophilus on rheology of stirred yoghurt. Int. J. Food Sci. Technol. 32: 213- 220.

Schellhaass SM, Morris HA (1985). Rheological and Scanning Electron Microscopic Examination of skim milk gels by fermenting with ropy and non-ropy strains of lactic acid bacteria. Food Microstruc. 4: 279287.

Stanbury PF, Whitaker A, Ha SJ (1995). Microbial growth kinetics. Principles of Fermentation Technology, $2^{\text {nd }}$ edition, pp. 13-16.

Szczesniak AS, Brandt MA, Friedman HH (1963). Development of standard rating scales for mechanical parameters of texture and correlation between the objective and sensory methods of texture evaluation. J. Food Sci. 28: 397-403.
Tamime AK, Robinson RK (1999). Background to manufacturing practices. Yoghurt Science and Technology. Woodhead Publishing Ltd. and CRC Press LLC, Boca Raton, Florida, pp. 11-619.

Toba T, Nakajima H, Tobitani A, Adachi S (1990). Scanning electron microscope and texture studies on characteristics consistency of Nordic ropy sour milk. Int. J. Food Microbiol. 11: 313- 320.

Tramer J (1973). Yoghurt Cultures. Nature 211: 204.

Vijayananda P, Mittal BK, Kulshreshtha M (1989). Instrumental Textural Profile Analysis of soybean curds prepared by acid and salt coagulation. J. Food Sci. Technol. 26(4): 223- 224.

Zucker TF, Zucker L (1943). Nutritive value of cotton, peanut and soy seeds. Ind. Eng. Chem. 35: 868- 871. 